\title{
Radiation-Induced Reduction of the Glial Population During Development Disrupts the Formation of Olfactory Glomeruli in an Insect
}

\author{
Lynne A. Oland, ${ }^{1}$ Leslie P. Tolbert, ${ }^{1}$ and Kenneth L. Mossman ${ }^{2}$ \\ 'Department of Anatomy and Cell Biology and 'Department of Radiation Medicine, Georgetown University School of \\ Medicine, Washington, D.C. 20007
}

\begin{abstract}
Interactions between neurons and between neurons and glial cells have been shown by a number of investigators to be critical for normal development of the nervous system. In the olfactory system of Manduca sexta, sensory axons have been shown to induce the formation of synaptic glomeruli in the antennal lobe of the brain (Hildebrand et al., 1979). Oland and Tolbert (1987) found that the growth of sensory axons into the developing antennal lobe causes changes in glial shape and disposition that presage the establishment of glomeruli, each surrounded by a glial envelope. Several lines of evidence lead us to hypothesize that the glial cells of the lobe may be acting as intermediaries in developmental interactions between sensory axons and neurons of the antennal lobe. In the present study, we have tested this hypothesis by using gamma-radiation to reduce the number of glial cells at a time when neurons of the antennal system are postmitotic but glomeruli have not yet developed. When glial numbers are severely reduced, the neuropil of the resulting lobe lacks glomeruli. Despite the presence of afferent axons, the irradiated lobe has many of the features of a lobe that developed in the absence of afferent axons. Our findings indicate that the glial cells must play a necessary role in the inductive influence of the afferent axons.
\end{abstract}

Interactions between neurons (reviewed by Jacobson, 1978; Edwards and Meyer, 1985; Purves and Lichtman, 1985) have been shown to govern cell survival (Cowan and Wenger, 1967; Berg, 1982; Fawcett and O'Leary, 1985), outgrowth, orientation, and sites of termination of neuronal processes (Murphey et al., 1975; Anderson, 1978; Macagno, 1979; Rakic, 1981; Shankland et al., 1982; Murphey and Lemere, 1984; Bastiani et al., 1985; Sretavan and Shatz, 1986), and the development and stabilization of synapses (Purves and Lichtman, 1980; Boss and Schmidt, 1984; Reh and Constantine-Paton, 1985). In very few cases (e.g., LoPresti et al., 1974), however, is the influence between the

\footnotetext{
Received Apr. 16, 1987; revised July 7, 1987; accepted July 17, 1987.

We wish to thank Sally Bates and Steven Grossman for their technical assistance with the scanning electron microscopic studies, Terrence Brennan for operating the cesium source and Oscar Rodbell for photographic assistance; Dr. D. Michael Jackson (Tobacco Research Laboratory, Oxford, N.C.) for generously supplying Manduca eggs; Drs. Joelle Presson, Paul St. John, and Jean Wrathall for critical review of the manuscript; and Dr. Arthur Popper for initial assistance with the scanning electron microscopy. This work was supported by NIH Postdoctoral Fellowship NS-07602 to L.A.O. and NIH Grant NS-20040 and BRSG funds to L.P.T.

Correspondence should be addressed to Dr. Lynne A. Oland, ARL Division of Neurobiology, Gould-Simpson Bldg., University of Arizona, Tucson, AZ 85721. Copyright (C) 1988 Society for Neuroscience $0270-6474 / 88 / 010353-15 \$ 02.00 / 0$
}

neurons (or axons) that were examined known to be direct rather than via other neurons, or even glial cells. The possibility of an intermediary role for glial cells must be considered because glial cells are known to have a number of other developmentally important roles: They are essential for guided outgrowth of axons (Silver and Sidman, 1980; Nordlander and Singer, 1982) and migration of neuronal cell bodies (Rakic, 1971) in vivo and, more recently, have been found to be instrumental in governing the morphological differentiation of neurons in vitro (DenisDonini et al., 1984; Mudge, 1984; Allen and Higgins, 1986).

Sensory systems have been used extensively to explore how afferent neurons affect the differentiation of their target neurons (e.g., LoPresti et al., 1973; Murphey et al., 1975; Woolsey et al., 1979; Sretavan and Shatz, 1986). Olfactory neurons, in particular, have been shown to induce the development of histologically distinct glomeruli in the first-order olfactory neuropils of both mammals (Graziadei and Samanen, 1980) and insects (Hildebrand et al., 1979; Schneiderman et al., 1982; Kent, 1985). The glomeruli are loci in which synaptic connections are concentrated and are thought to operate as functional units in the processing of olfactory information (Ernst et al., 1977; Stewart et al., 1979; Chambille et al., 1980; Lancet et al., 1982; Stocker et al., 1983; Christensen and Hildebrand, 1984).

We have begun to explore the cellular basis for the induction of glomeruli in the antennal system of the moth Manduca sexta. In a previous paper (Oland and Tolbert, 1987), we showed that the growth of sensory axons from the external olfactory organs, the antennae, into the antennal lobes of the brain of Manduca initiates a stereoty ped sequence of changes in shape and position of neuropilar glial cells. These changes presage the creation within the neuropil of spheroidal knots of neuropil, the glomeruli, separated from each other by glial borders (Fig. 1 $A$ ). When sensory axons are prevented from entering the lobe, the glial cells remain in their immature configuration and the neuropil subsequently fails to become segregated into glomeruli (Fig. $1 B$; Oland and Tolbert, 1987). The fact that glial-cell changes precede glomerulization during normal development and fail to occur in unafferented lobes that subsequently do not become glomerular suggested to us the possibility that, in Manduca sexta. glial cells may mediate some of the effects of sensory axons on their target neurons in the antennal lobe.

In this study, we reduced the number of glial cells with gamma-irradiation to determine whether glial cells are necessary intermediaries in the influence of sensory axons on the development of the antennal lobe. If they are necessary, the neuropil of a glial-deficient antennal lobe should resemble that of an 


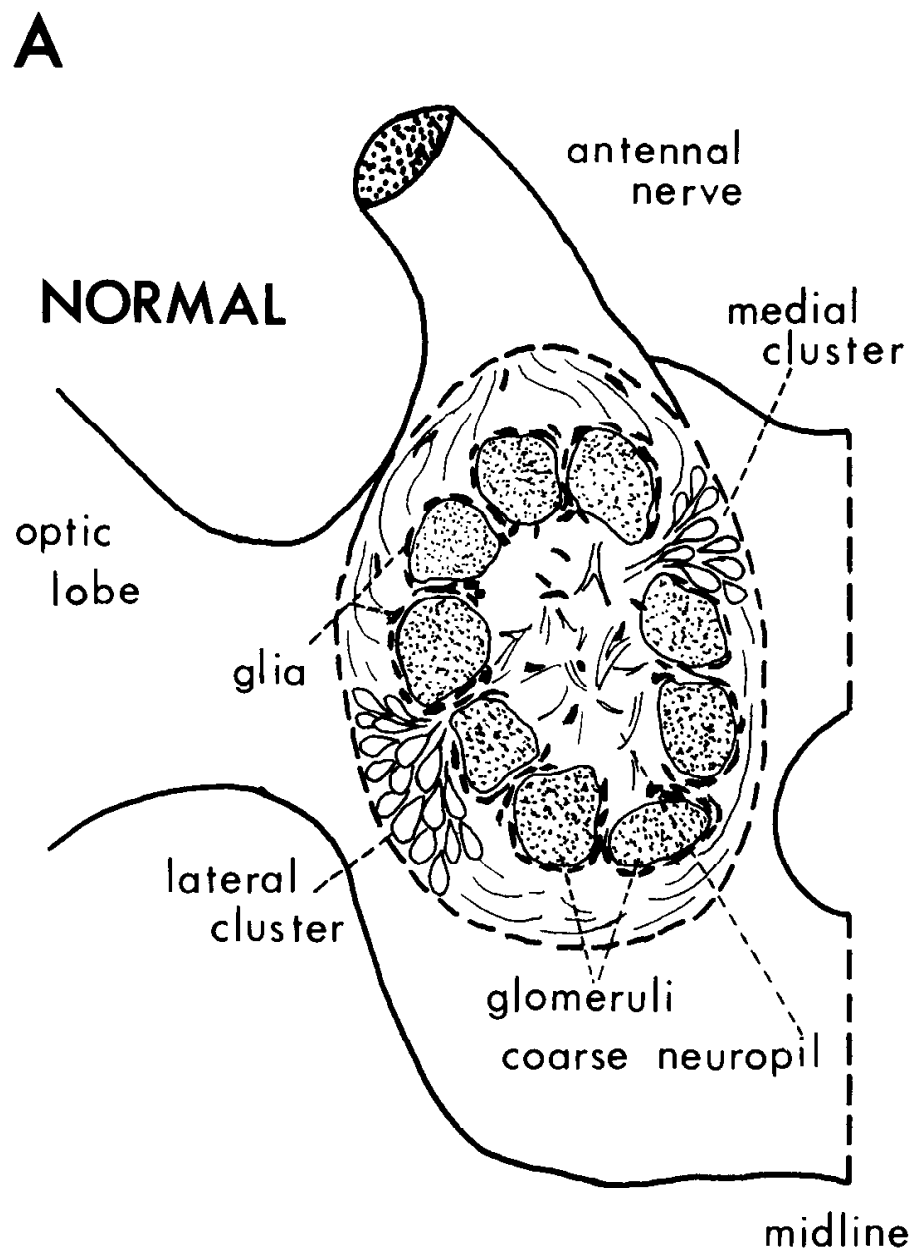

\section{UNAFFERENTED}

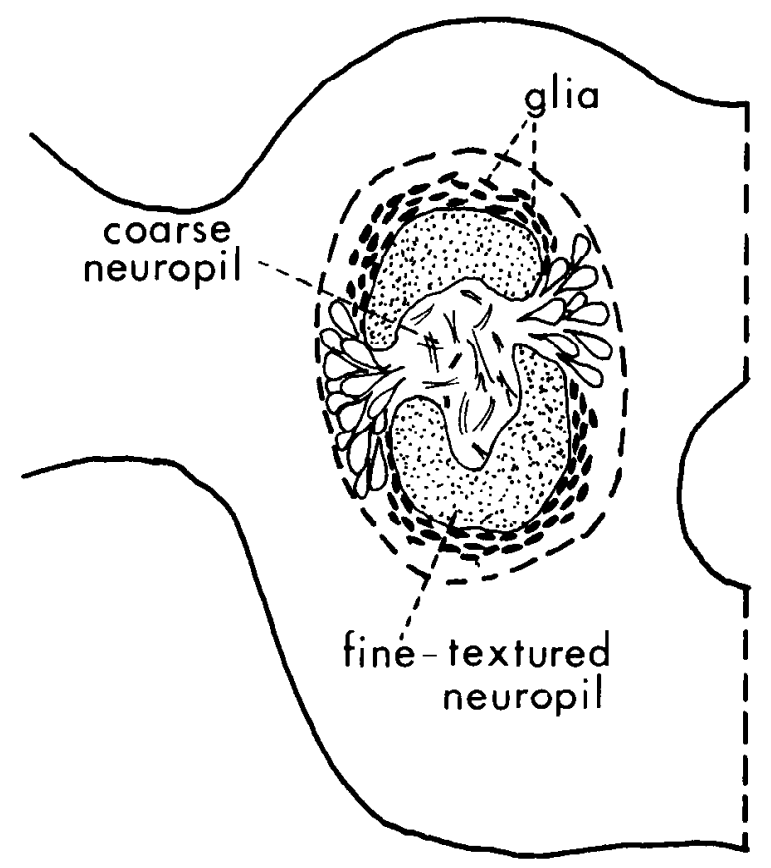

Figure 1. Schematic drawing indicating salient features of normal mature antennal lobes and mature antennal lobes that developed in the absence of antennal afferent axons (summarizing results of Oland and Tolbert, 1987).

unafferented lobe. If they are not necessary, their absence should not affect the induction of glomeruli by the sensory axons.

Some of these results have been reported in an abstract (Oland and Tolbert, 1986).

\section{Materials and Methods}

Animals. Manduca sexta were reared from eggs as described by Sanes and Hildebrand (1976a). Metamorphic development in Manduca proceeds over 18 stages [equivalent to the 18 staged "days" of previous papers (e.g. Tolbert et al., 1983)], beginning at the time of the larvalpupal molt (pupation). The developmental stage of a metamorphosing animal was determined as in our previous study (Oland and Tolbert, 1987) by observation of morphological changes of the cuticle or of structures visible through the cuticle.

Irradiation protocol. Animals were exposed to gamma-irradiation in a cesium-137 source (Gammaradiator model 100, Best Industries, Inc., Springfield, VA). Animals received whole-body radiation at room temperature at a distance of $21 \mathrm{~cm}$ from the 67 -teraBecquerel $(1800 \mathrm{Cu})$ cesium source. The dose rate at the position of the animals in the radiation field was calculated to be 2.64 Gray (Gy; 1 Gray $=100$ rads)/ min. The dose rate was determined using a Victoreen condensor $\mathbf{R}$ meter cross-calibrated to a National Bureau of Standards-calibrated dosimeter.

The doses we administered were in the range used to sterilize male insects in field studies of pest control methods (see Discussion) (LaChance et al., 1967). Each animal received either a single dose of 200 , 400 , or 800 Gy during stage 4/early stage 5 or a total dose of either 800 or $1600 \mathrm{~Gy}$ given in 2 equal fractions, the first during stage 4/early stage 5 and the second 18-24 hr (less than one developmental stage) later.
These stages were chosen because previous studies showed that sensory neurons of the antenna have undergone their final mitoses by the end of stage 3 (Sanes and Hildcbrand, 1976b), and neurons of the antennal lobe are postmitotic by the end of stage 2 (K. S. Kent, personal communication; L. A. Oland and L. P. Tolbert, unpublished observations). Glial cells proliferate from early in metamorphosis through at least slage 12 (L. A. Oland and L. P. Tolbert, unpublished observations). Features characteristic of glomeruli begin to emerge during stage 5. Stage 4 and early stage 5 , therefore, provided a window of time subsequent to tinal neuronal mitoses but prior to the development of glomeruli during which we could interfere preferentially with glial cell proliferation (Fig. 2). Most animals were sacrificed at stage 12 or 13 because by stage 12 , the antennal lobe has the histological appearance of a mature lobe (Tolbert et al., 1983); 4 animals were allowed to develop to stage 15/16.

Histology and electron microscopy. Animals were anesthetized by cooling on ice. Each brain was removed still encased in the muscle and cuticular tissue that surround it and immersed in cold fixative solution overnight. The fixative solution contained $2.5 \%$ glutaraldehyde, $0.5 \%$ paraformaldehyde, $0.18 \mathrm{mM} \mathrm{CaCl}_{2}, 0.58 \mathrm{~mm}$ sucrose, and $0.1 \mathrm{M}$ sodium cacodylate buffer, pH 7.4 (modified from Karnovsky, 1965). After the dissection was completed, the brains were osmicated en bloc $(0.05 \%$ for light microscopy, $1.0 \%$ for electron microscopy), postfixed in $1.0 \%$ uranyl acetate (for electron microscopy), and dehydrated through a graded series of ethanols and embedded in Epon/Araldite. For light microscopy, $1 \mu \mathrm{m}$ sections were cut, stained with toluidine blue, and mounted in Permount. For electron microscopy, thin sections were stained with lead citrate and examined in a JEOL $100 \mathrm{~S}$ electron microscope.

Sections of antennal lobes of normal and chronically unafferented animals prepared for our previous studies (Oland and Tolbert, 1987) were also used for comparison with lobes of experimental animals.

In addition to the glomeruli, another specialized region of neuropil 
called the macroglomerular complex is present in antennal lobes innervated by male antennae (Schneiderman et al., 1982). It comprises the terminal arbors of afferent axons of sensory neurons innervating the male-specific trichoid sensilla and the higher-order branches of a subclass of antennal-lobe neurons that respond to female sex pheromone (Matsumoto and Hildebrand, 1981). It does not resemble ordinary glomeruli in texture or neuritic branching patterns (Matsumoto and Hildebrand, 1981), nor does it possess a complete glial border; therefore, we have not focused on its development.

\section{Quantitative analyses}

Number of glial cells. The central core of the antennal lobe is a region composed of large-diameter processes, easily distinguished histologically from the surrounding fine-textured (homogeneously staining) synaptic neuropil. Once the coarse neuropil was identified in histological cross section, 45-60 sections, $1 \mu \mathrm{m}$, were taken serially. For each antennal lobe (see Table 1), camera lucida drawings at $100 \times$ magnification were made from 2-3 sections (separated by at least $10 \mu \mathrm{m}$ ) through the middle of the lobe. Each drawing showed the position of all nuclei of neuropil-associated glial cells as well as the boundaries of the finetextured neuropil. These glial cell nuclei (Wigglesworth's type iv) are distinguished from other classes of glial cells by their positions in the nervous system (Wigglesworth, 1972; Strausfeld, 1976; Lane, 1981) and from the large $(\sim 8-10 \mu \mathrm{m})$ neuronal nuclei by their size $(2-3 \mu \mathrm{m}$ in their shortest dimension), irregular shape, and pattern of chromatin. The glial-cell nuclei from each section were counted and an average value per cross-section calculated for each antennal lohe.

Number of antennal-nerve axons. One-micron cross sections and adjacent thin sections of one or both antennal nerves of 4 irradiated animals and one normal animal were cut at a level just proximal to the base of the antenna (in the region of the bifurcation of the antennal nerve into 2 branches as it enters the scape of the antenna). At this level, a small motor branch innervating the antennal musculature in the head has already diverged from the antennal nerve (Zacharuk, 1985) so that the nerve comprises only mechanosensory and antennal sensory afferent axons. For each nerve sectioned, we made a camera lucida drawing at $100 \times$ magnification that included the outline of the nerve just inside the perineurium and the outline of regions occupied almost exclusively by large $(0.8-2.5 \mu \mathrm{m})$ diameter axons presumed to be mechanosensory (Camazine and Hildebrand, 1979; Zacharuk, 1985). The area occupied by the small-diameter axons was determined using the Bioquant II Digitizing Morphometry program (on an Apple IIe computer). For each nerve, we constructed a low-magnification $(2000 \times)$ electron-micrograph montage spanning the diameter of the nerve and a higher-magnification $(5000 \times)$ montage of a region along the diameter equivalent to $2-5 \%$ of the area of the nerve. At $5000 \times$, axons, with diameters of approx. $0.2-0.3 \mu \mathrm{m}$, can be distinguished from small glial processes by

\begin{tabular}{lcllll}
\hline Table 1. & \multicolumn{5}{l}{ Summary of experimental analyses } \\
$\begin{array}{l}\text { Dose } \\
\text { (Gy) }\end{array}$ & $\begin{array}{c}\text { LM of } \\
\mathrm{AL}^{a}\end{array}$ & $\begin{array}{l}\text { EM of } \\
\text { AL }\end{array}$ & $\begin{array}{l}\text { EM of } \\
\text { AN }\end{array}$ & $\begin{array}{l}\text { LM of } \\
\text { ant. }\end{array}$ & $\begin{array}{l}\text { SEM of } \\
\text { ant. }\end{array}$ \\
\hline 200 & $8(2)$ & - & - & - & - \\
400 & $3(3)$ & - & 1 & 3 & 3 \\
$400 \times 2$ & $19(9)^{h}$ & 4 & $4 c$ & 12 & 8 \\
800 & $5(4)$ & 1 & - & - & -
\end{tabular}

${ }^{a}$ Total number followed in parentheses by number of antennal lobes in which camera lucida drawings were made (see "Counts of number of glial cells" above)

${ }^{\circ}$ Four of these antennal lobes were from stage $15 / 16$ animals.

'The axon counts were made in antennal nerves from 4 animals whose brains were also examined at the LM and EM levels and whose antennae were examined at the LM and SEM levels. In I animal, axon counts were made in both antennal nerves.

the presence of large amounts of glycogen and rough endoplasmic reticulum in the glial processes. An estimate of the number of antennal afferent axons in the entire nerve was made by counting the axons in the $5000 \times$ montage (thus compensating for variations in the proportion of the nerve occupied by glia), determining the area occupied by the montage, and extrapolating to the area occupied by the small-diameter fibers of the antennal nerve.

Scanning electron microscopy of antennae. Antennae from normal and irradiated animals were air dried, then $\mathrm{CO}_{2}$-critical point dried using amyl acetate as the intermediary fluid, mounted on aluminum stubs, coated with gold-iridium, and viewed with an Hitachi 570 scanning electron microscope.

\section{Results}

\section{General effects of radiation}

The development of irradiated animals was essentially normal. At doses higher than $400 \mathrm{~Gy}$, however, certain features were distorted: leg spines were often bulbous or enlarged, eye pigment was patchy, head and wing scales were sparse, and cuticular structures were softer than normal, especially in older animals. At the higher doses used, animals typically reached stage 15/16 but then ceased further development and did not eclose.

\section{Effect of irradiation on the antennal lobe}

Exposure of animals to radiation at stage $4 / 5$, when sensory and antennal-lobe neurons are postmitotic but glial cells arc still

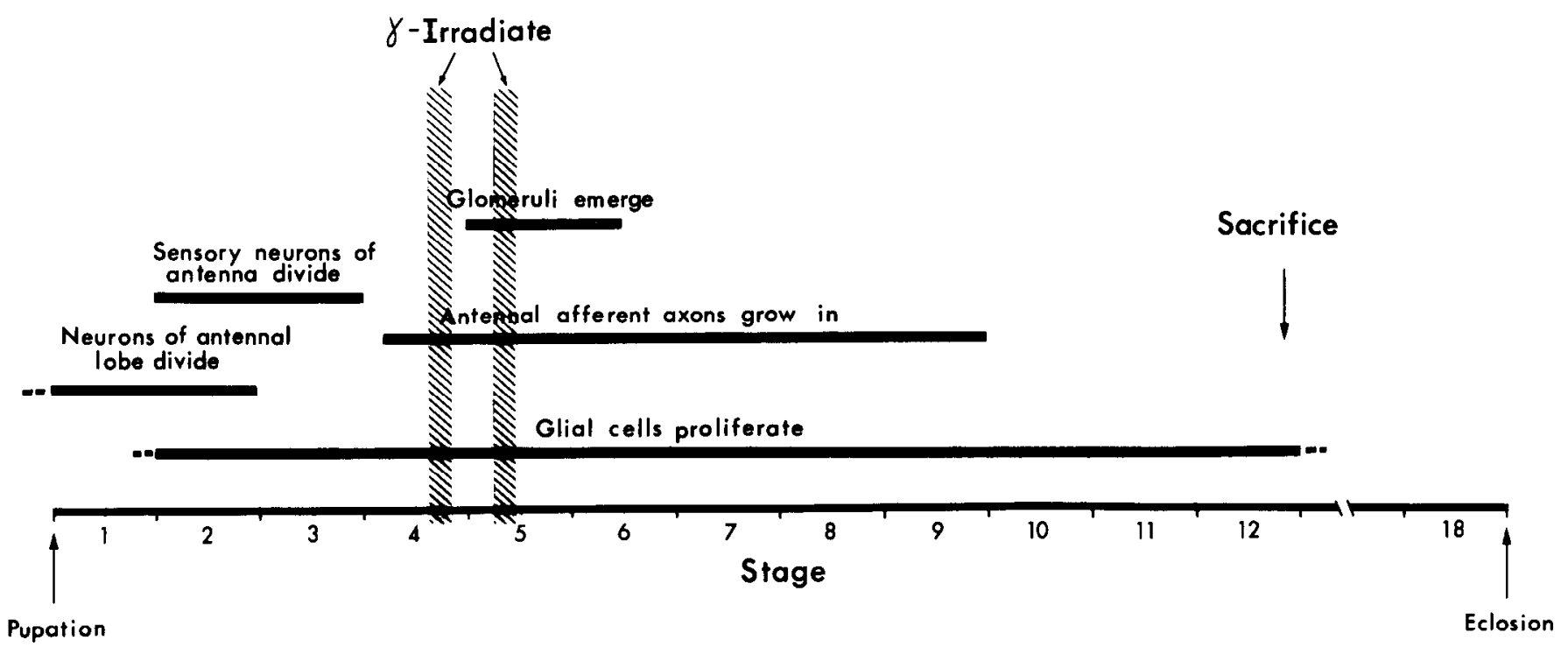

Figure 2. Summary timetable of developmental events in Manduca antennal system (taken from our own work and Sanes and Hildebrand, 1976b) indicating timing of irradiation procedure. Animals were usually sacrificed at stage $12 / 13$, as indicated. 


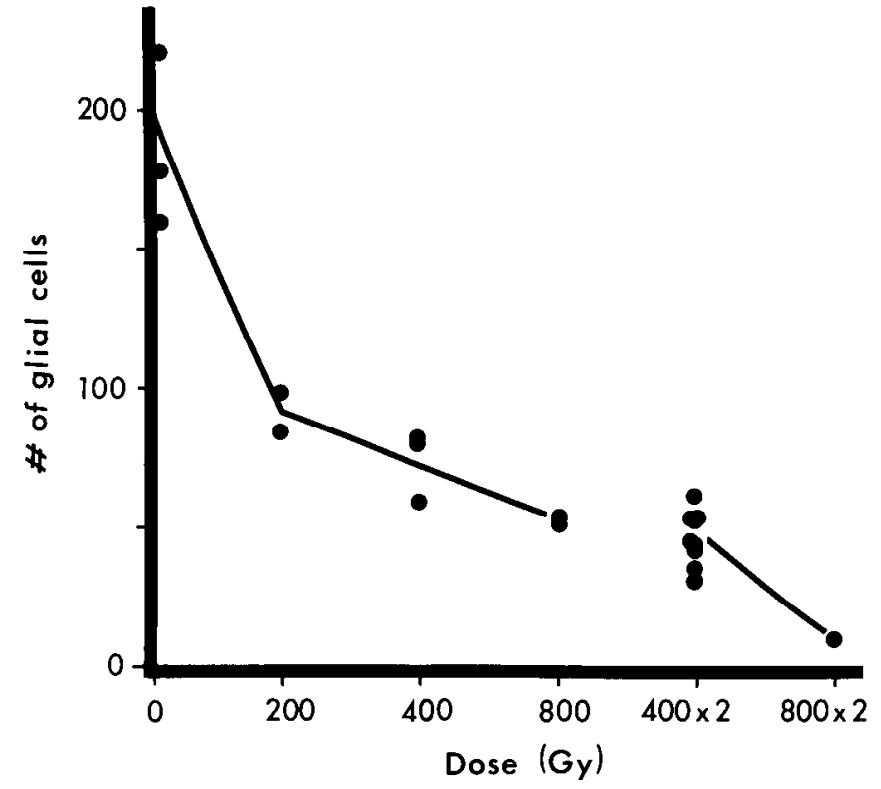

Figure 3. Reduction of number of glial cells by different doses of radiation. Number of glial cells per cross section, averaged from 2-3 sections, $1 \mu \mathrm{m}$, through the center of the lobe, is plotted against radiation dosage. Each point represents 1 animal; lines connect mean values for each dose of radiation.

proliferating (Fig. 2), results in a dose-dependent reduction in the number of glial cells present at stage 12. Figure 3 gives the average number of glial cells in cross sections through the centers of normal lubes and lobes given single or fractionated doses of radiation. The dose of 800 Gy was fractionated as 2 doses of 400 Gy separated by $18-24 \mathrm{hr}$ in order to achieve the greatest possible reduction in number of glial cells while at the same time minimizing nonspecific damage (Jefferies and Cornwell, 1958 , and see below). When the dose is fractionated, the resulting reduction in number of glial cells is the same as at the single 800 Gy dose.

As glial numbers are reduced, the neuropil of the antennal lobe becomes less glomerular. The sections shown in Figure 4 permit comparison of the histology of antennal lobes exposed to different doses of radiation $(C-F)$ with that of a normal lobe $(A)$ and of one that had been deprived chronically of its antennal afferent input (unafferented) $(B)$. In the normal lobe ( $A$; see also Fig. 1), the glomeruli are distinct spheroidal knots of fine-textured neuropil. Glial-cell bodies and processes, which usually stain more darkly than other antennal-lobe elements, surround each of the glomeruli but are excluded from the interiors of the glomeruli. Many glial cells are also interspersed among the largediameter processes that form the central coarse region of the neuropil. Antennal afferent axons, which provide the overwhelming majority of inputs to the antennal lobe (Hildebrand and Montague, 1986), course around the perimeter of the neuropil; bundles diverge and enter the glomeruli from the outside. From their positions outside the neuropil, antennal-lobe neurons send their primary neurites in to the center of the lobe, where their primary branches form the coarse neuropil.

In contrast, the synaptic neuropil of an unafferented lobe at the same stage (Fig. $4 B$; see also Fig. 1) is not organized into discrete glomeruli but merely forms a ring of fine-textured neuropil that has been described as "protoglomerular" (Hildebrand et al., 1979). Glial cells form a distinct rim, 4-5 cell bodies thick, around the outside of the neuropil that differs little from that seen in the earliest stages of adult development except in its width. Almost no glial processes penetrate the ring of neuropil, and few glial cells are found in the center of the lobe (Oland and Tolbert, 1987). The border between the coarse- and finetextured neuropils is convoluted, as large-diameter neurites extend deep into the ring of fine neuropil.

Panels $C-F$ (Fig. 4) show the effect on the antennal-lobe neuropil of increasing doses of radiation. At $200 \mathrm{~Gy}(C)$, the lobe is still obviously glomerular, although the number of glial cells has decreased by about half (see Fig. 3). Each glomerulus has a glial envelope, and glial cells can be found within the central coarse neuropil. At $400 \mathrm{~Gy}$ ( $D$; with about one-third the normal number of glial cells), some regions of the lobe contain knots of fine-textured neuropil reminiscent of glomeruli, while other regions lack glomeruli altogether. Some "glomeruli" are surrounded by incomplete glial borders, giving the outer edge of the neuropil a scalloped appearance. At $800 \mathrm{~Gy}(F$; with about one-fourth the normal number of glial cells), there are no glomeruli. The neuropil merely segregates into concentric fine- and coarse-textured regions. The abrupt boundary between the coarse- and fine-textured regions characteristic of a normal lobe is absent; instead, the interface between the 2 regions has thin neuritic processes intcrspersed with large-diameter processes as in the unafferented lobe. The outer edge of the fine-textured neuropil is marked by bundles of afferent axons, which at high magnification can be seen to dive into the fine-textured neuropil. Glial cells extend processes, and some glial cells can be found in the central coarse neuropil. There is evidence of some tissue disruption, particularly at the electron-microscopic level. Nevertheless, the basic ultrastructural organization of the lobe (Fig. $5 A$ ) is seen to have developed normally (note layering of cell bodies, axons, fine-textured neuropil), and the antennal nerve is organized into fascicles surrounded by glial processes, as in the normal case (Fig. $5 B$ ). Although at the 800 Gy dose there are vacuoles, lysosomal debris, degenerated material, and (not shown) slightly folded nuclear membranes in the neuronal cell bodies, we did not see deep clefts in the nuclear membranes of neurons, eccentric nuclei, extensive vacuolization or swelling of ncuronal nuclei or cytoplasm, or distortion of mitochondria or other organelles, all of which typically appear in mammalian cells subjected to high doses of gamma- or X-irradiation (Quastel and Pomerat, 1963; Masurovsky et al., 1967; Rubin and Casarett, 1968; Casarett, 1980; Mettler and Moseley, 1985).

When the 800 Gy dose is fractionated into 2 doses of 400 $\mathrm{Gy}$, the resulting antennal-lobe neuropil has the same features as after a single 800 Gy dose, but there is little evidence of direct damage to neurons. Therefore, the detailed analyses that follow were performed on antennae and antennal lobes from animals exposed to this dose. Figure $6 A$ shows, at the electron-microscopic level, that the basic organization of the antennal-lobe neuropil has remained intact and also confirms at the ultrastructural level the light-microscopic observation that there is minimal evidence of direct damage within cells. Neuronal cell bodies lie outside the neuropil. Glial-cell nuclei, when present, have the normal irregular shape and chromatin pattern. Antennal afferent axons appear at the external margin of the fine-textured neuropil, and the neuropil is seen as a tightly packed tangle of fine neuronal processes. Higher magnification of the fine-textured neuropil (Fig. $6 B$ ) reveals numerous synapses with features characteristic of synapses normally found in the neuropil of a stage $12 / 13$ antennal lobe, i.e., profiles filled with round, clearcentered vesicles or mixed populations of clear, round, and 

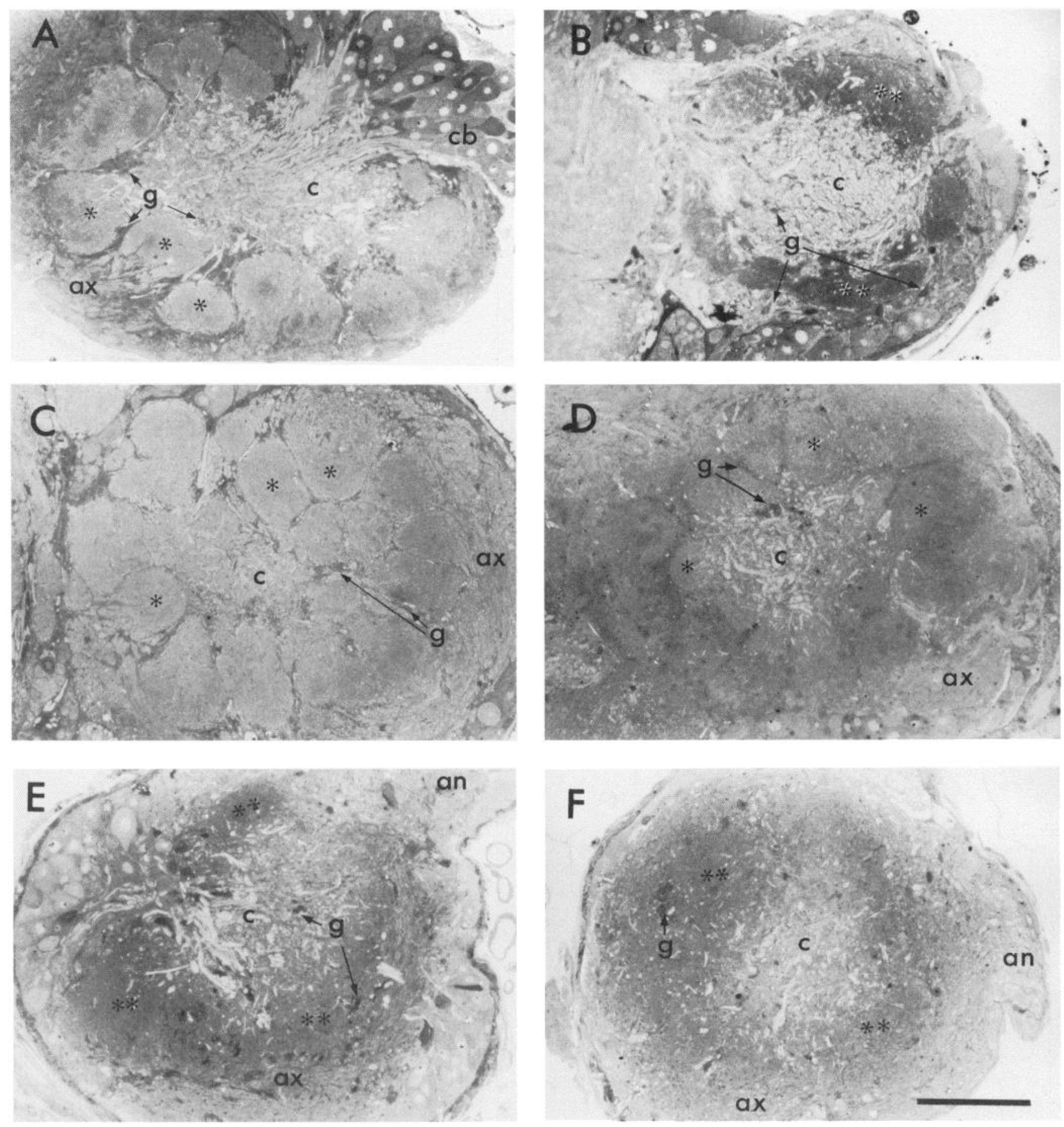

Figure 4. Histological sections through stage $12 / 13$ antennal lobes. Scale bar, $100 \mu \mathrm{m}$ for all panels. $A$, Normal antennal lobe. $B$, Unafferented lobe. $C-F$, Lobes from animals that had been exposed to increasing doses of radiation: $C, 200 \mathrm{~Gy} ; D, 400 \mathrm{~Gy} ; E, 800 \mathrm{~Gy} ; F, 400 \mathrm{~Gy} \times 2$. an, antennal nerve; $a x$, antennal afferent axons within lobe; $c$, coarse central neuropil; $c b$, cell bodies of antennal-lobe neurons; $g$, glial cells; ${ }^{*}$, glomeruli; **, fine-textured neuropil that is not subdivided into glomeruli.

larger, dense-cored vesicles and triangular or rod-shaped presynaptic densities (Tolbert et al., 1983). In contrast, synapses are rare in the coarse neuropil (Fig. 6C), as in normal lobes.

Figure 7 provides additional evidence of the integrity of neuronal elements of the antennal lobe after exposure to $400 \mathrm{~Gy} \times$ 2. Organelles within neuronal cell bodies look normal (Fig. 7A): there is no evidence of the disruption seen at the single $800 \mathrm{~Gy}$ dose. Axons coursing within the antennal nerve (Fig. $7 B$ ) have the typical normal diameter of about $0.2-0.3 \mu \mathrm{m}$ and have an electron-lucent cytoplasm that contains the normal complement of mitochondria, microtubules, and small membranous structures. There are few ultrastructurally obvious effects of irradiation in the nerves, though in some irradiated nerves we did see some swollen axons and areas devoid of axons as well as multilamellar and multivesicular bodies. In most of our preparations the glial investment of the antennal nerve was clearly 

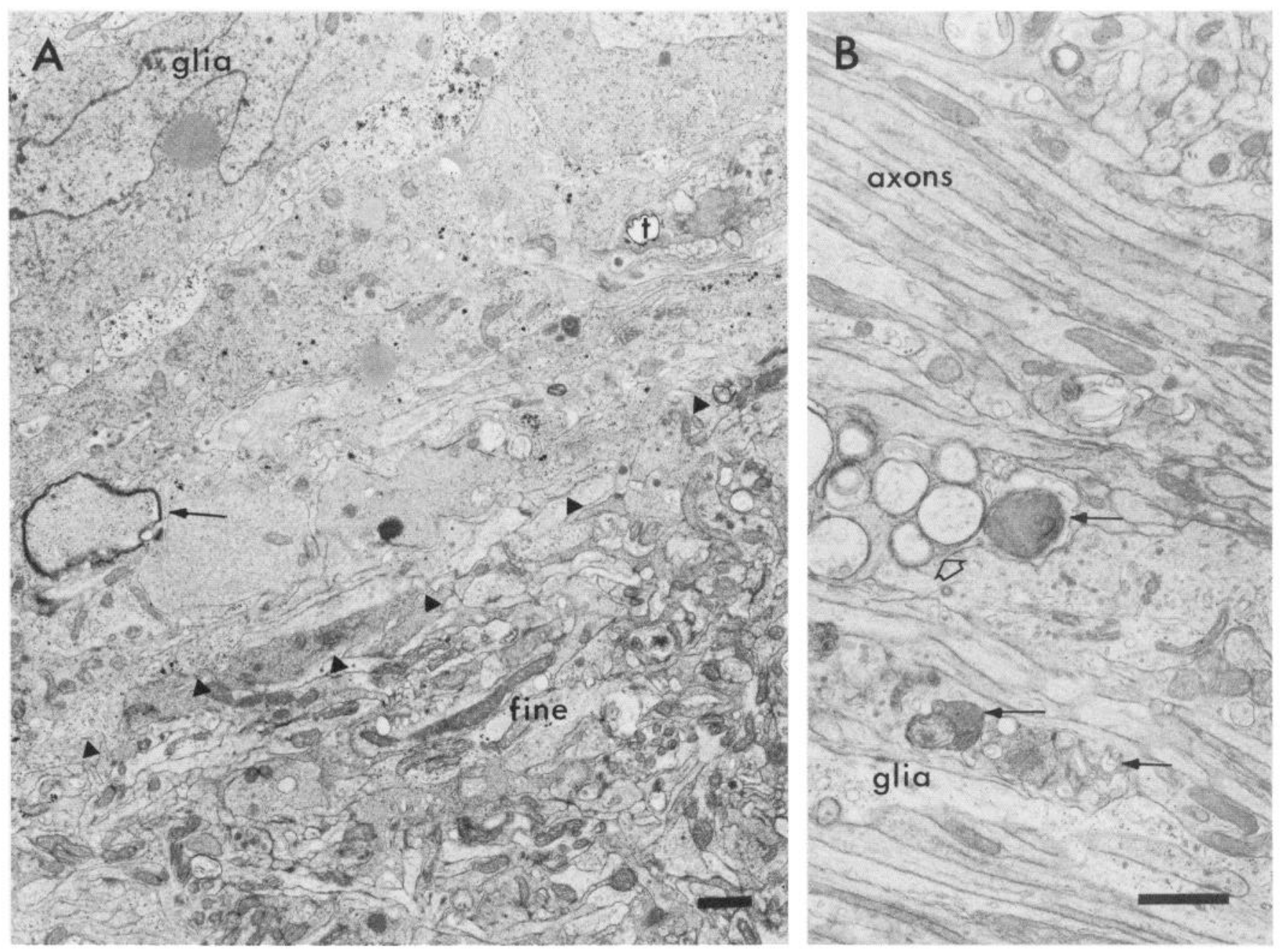

Figure 5. Electron micrographs of stage 13 antennal lobe from an animal that had been exposed to $800 \mathrm{~Gy}$. Scale bars, $1 \mu \mathrm{m} . A$, Outer edge of fine-textured neuropil. $t$, tracheole; triangles, border between fine-textured neuropil and glial processes; arrow, glial process wrapped by unusual number of membranes. $B$. Antennal afferent axons coursing around perimeter of lobe. Open arrow, vacuolated region; arrows, lysosomal structures containing dense multilamellar debris.

reduced compared with that of normal nerve, but there was considerable variability among preparations in the proportion of the nerve occupied by glial cytoplasm.

Other major structures of the insect brain such as the central body, mushroom bodies, and optic lobes (Fig. $8 \mathrm{~A}$ ) retain their normal position and histological organization. In addition, the macroglomerular complex, the characteristic structure of male, but not female, antennal lobes was always present in irradiated males (Fig. 10A).

Could the failure of the antennal lobes to develop glomeruli be the result of radiation-induced deafferentation rather than of a reduction in the number of glial cells? In order to explore this possibility, we examined several aspects of the antennal input in animals that had received $400 \mathrm{~Gy} \times 2$. The basic organization of the antenna always developed normally despite the high dose of radiation. In many animals, however, distal portions of the antennal flagellum developed poorly or were unlikely to contribute significant numbers of axons to the antennal nerve because a clot of hemolymph obstructed axonal growth toward the head. These animals were always discarded. Figure 9 shows scanning electron micrographs of portions of stage 12 or 13 antennal flagella from normal and irradiated animals with complete antennae. Comparison reveals that the overall features of normal antennae, such as the pattern of long trichoid sensilla on male antennae and that of the shorter sensilla on both male and female antennae (Sanes and Hildebrand, 1976a), are also present in irradiated antennae. Although some cuticular disruption was always present, typically seen as malformation of the sensilla and the stellate microtrichia surrounding them, the amount of disruption varied and in no case was there omission of either the trichoid or shorter classes of sensilla. Cross sections through the antennal flagellum at the level of the fourth or fifth segment distal to the base (Fig. 8, B, C) consistently showed dendrites of the olfactory receptor neurons ensconced within the hairs. Portions of the sensory epithelium itself usually showed some disruption in uniformity, but the iterative pattern formed by the sensory neurons and their support cells usually remained discernible. Fascicles of axons from the sensilla leave the epithelium to join the antennal nerve as it courses along the length of the flagellum. 

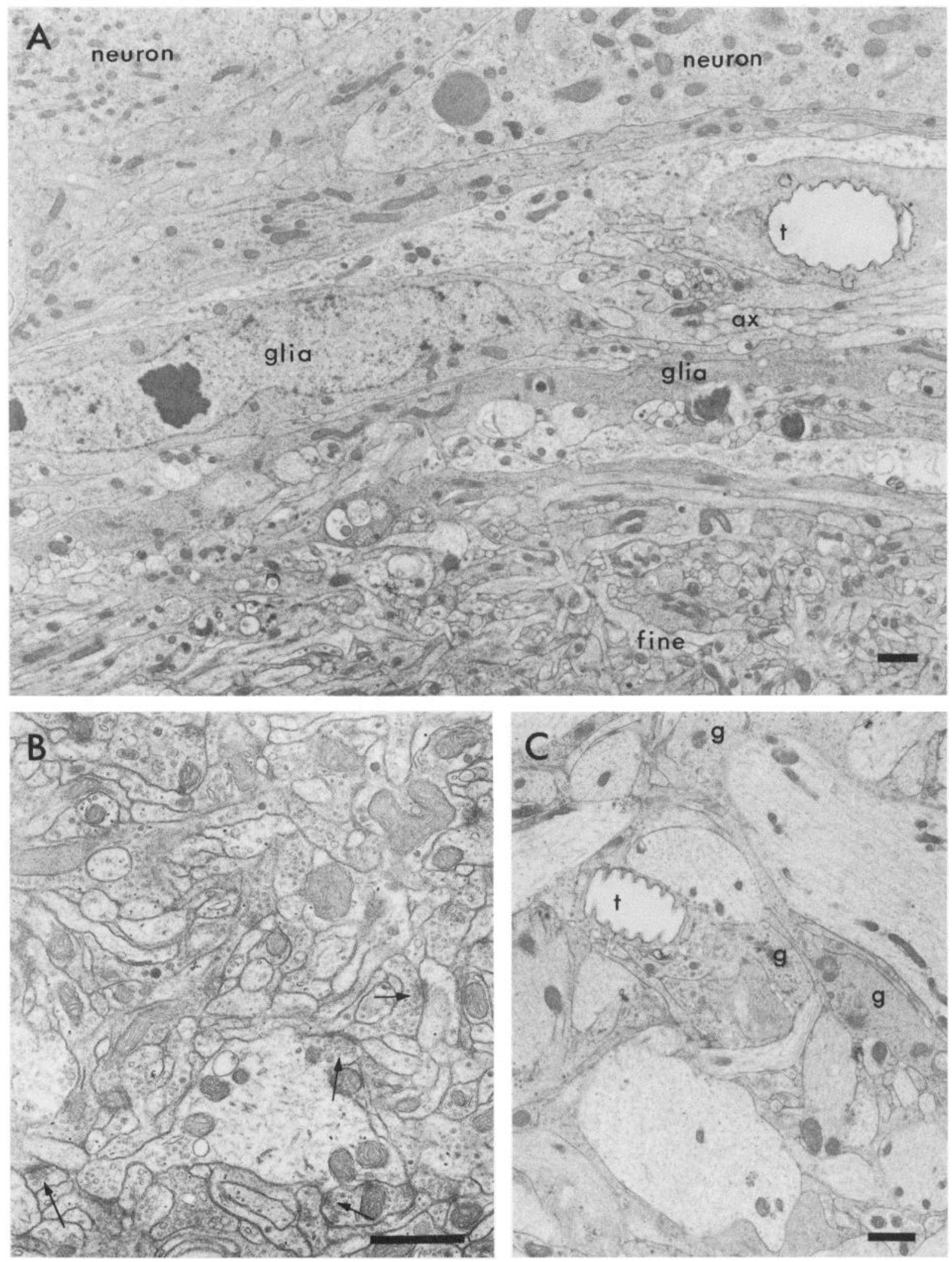

Figure 6. Electron micrographs of stage $12 / 13$ antennal lobes from animals that had been exposed to $400 \mathrm{~Gy} \times 2$. Scale bars, $1 \mu \mathrm{m}$. $A$, Outer edge of fine-textured neuropil. $a x$, afferent axons; $t$, tracheole. $B$, Fine-textured neuropil. arrows, synapses. $C$, Central coarse neuropil. Large electronlucent profiles are neurites. $g$, glial processes; $t$, tracheole. 

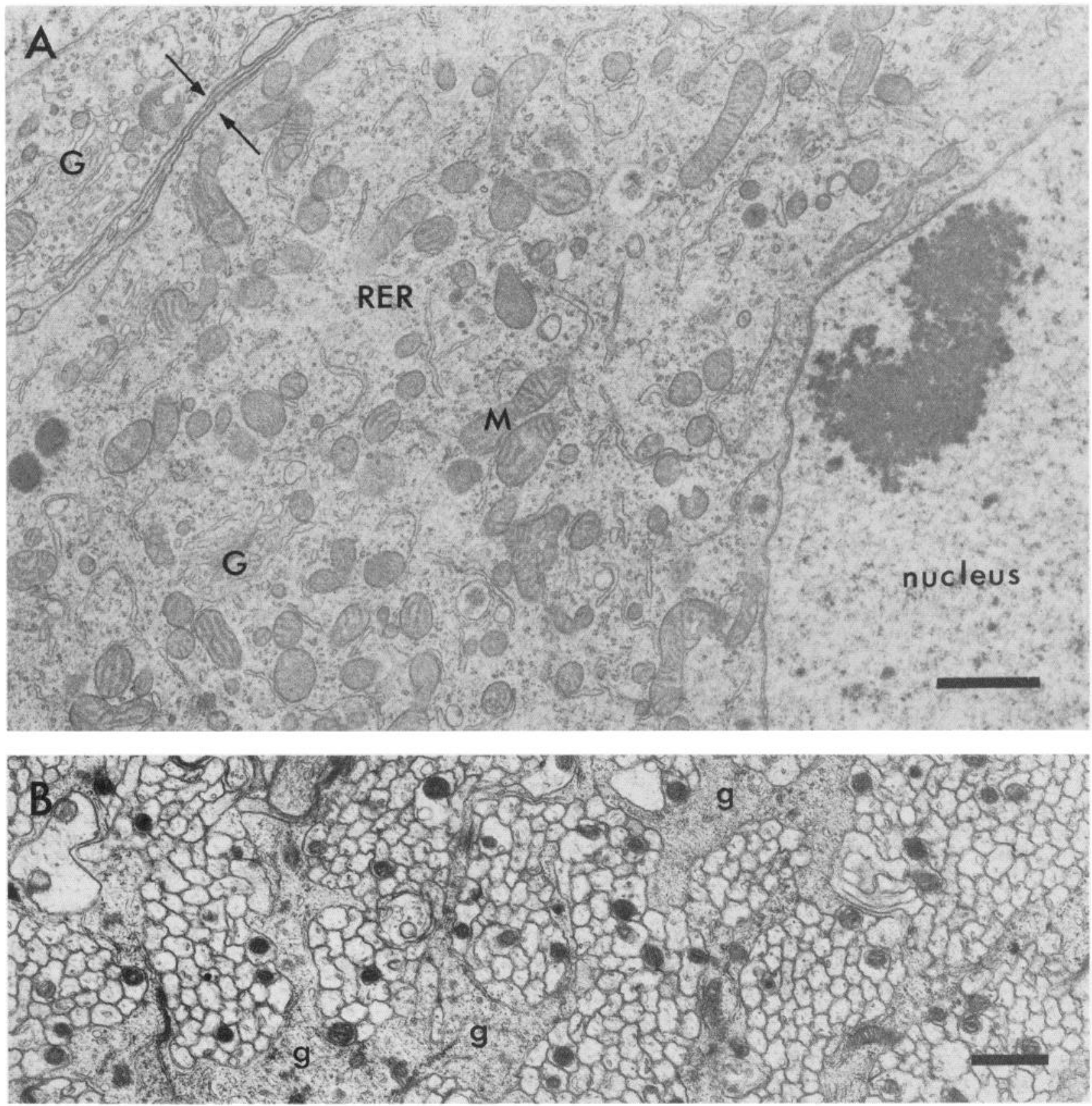

Figure 7. Electron micrographs of stage $12 / 13$ neuronal cell body and antennal nerve from animals that had been exposed to $400 \mathrm{~Gy} \times 2$. Scale bars, $1 \mu \mathrm{m}$. $A$, Portions of cell bodies of 2 antennal-lobe neurons and intervening glial processes (between arrows). $G$, Golgi apparatus; $M$, mitochondrion, showing normal cristae; $R E R$, rough endoplasmic reticulum. $B$, Portion of cross-sectioned antennal nerve containing glial processes, $g$, and multiple electron-lucent axons.

Because the best test of our hypothesis would be the appearance of antennal lobes from animals in which the number of glial cells had been severely reduced and in which the antennal input was known to be adequate (see Discussion), we carried out a complete analysis of the antennal system of 4 animals (2 males and 2 females) that had been exposed to $400 \mathrm{~Gy} \times 2$. Our analysis included SEM of the antenna, counts of axons in the antennal nerve, and counts of neuropil-associated glial cells, as well as examination of the lobes at the light-microscopic level. Two of the lobes were also viewed in the EM to permit more detailed assessment both of the ultrastructural organization of the fine- and coarse-textured neuropil and of any disruption that might be attributed to radiation. In each case, the antennae showed all the features characteristic of normal antennae (as in Fig. 9). The number of afferent axons in a normal (female) antennal nerve was estimated to be 306,000 , and in antennal nerves from irradiated animals ranged from 76,000 to 321,000 . [The number of axons in a normal mature male antennal nerve has been reported previously to be 260,000 (Sanes and Hildebrand, 1976b).] In the EM, we saw minimal evidence of cellular damage and the fine- and coarse-textured neuropil was as shown in Figure 6. For Figure 10, we selected 3 antennal lobes from this group. The lobe in $A$ had approximately $30 \%$ of the normal number of axons, and the average number of glial cells per cross section was $32 \%$ of normal; the lobe in $B$ had $50 \%$ of the axons and $21 \%$ of the glial cells; the lobe in $C$ had $82 \%$ of the axons 

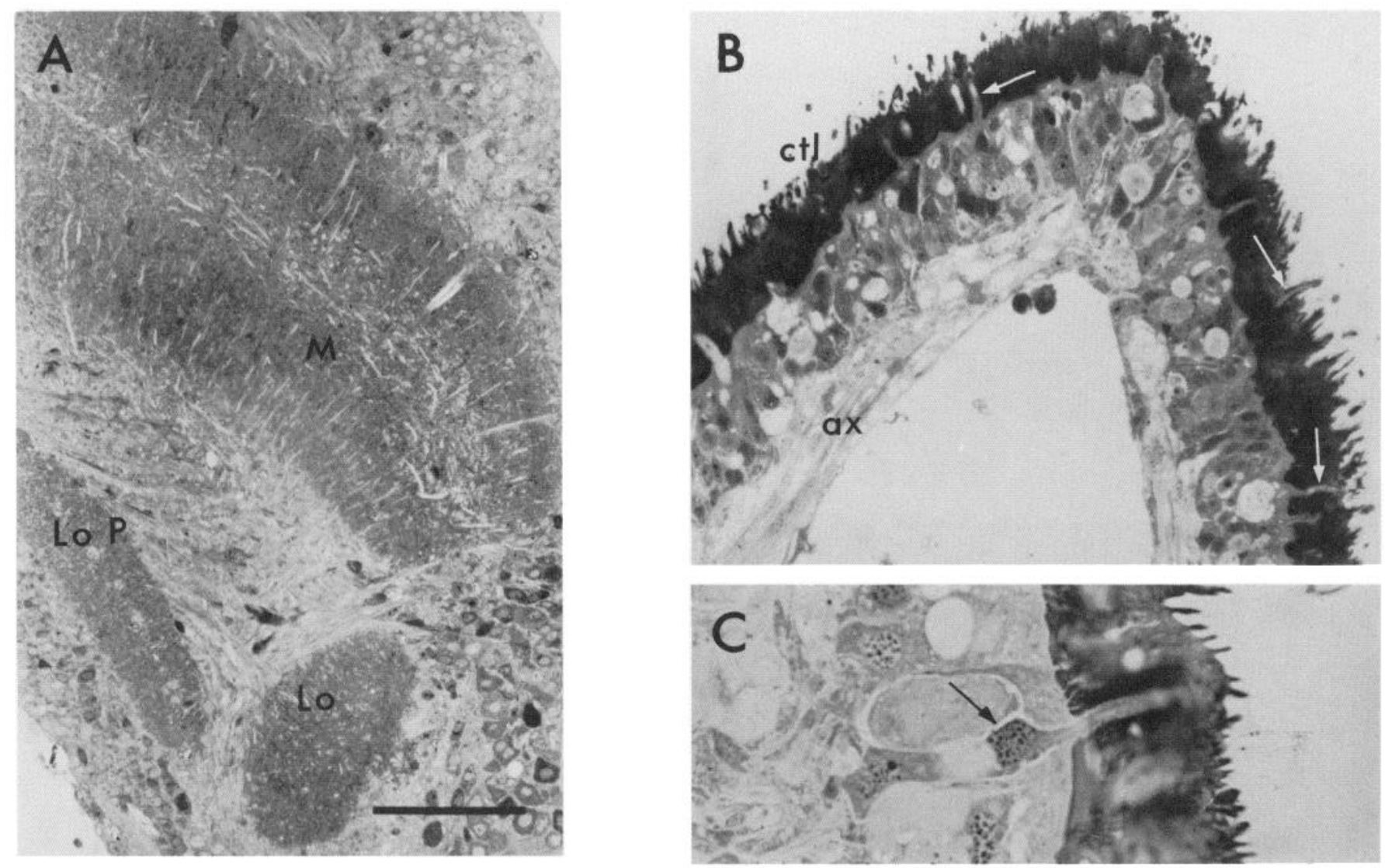

Figure 8. Histological sections from an animal that had been exposed to $400 \mathrm{~Gy} \times 2$. Scale bar, $100 \mu \mathrm{m}$ in $A, 34 \mu \mathrm{m}$ in $B$, and $18 \mu \mathrm{m}$ in $C$. $A$, Portion of optic lobe. $M$, medulla; $L o$, lobula; $L o P$, lobula plate. $B$, and $C$, Cross section through antenna. $a x$, afferent axons; $c t l$, cuticle; arrows, dendrites of olfactory sensory neurons extending into cuticular hairs.

and $26 \%$ of the glial cells. In each case, the neuropil was divided into concentric fine- and coarse-textured regions, but none of these lobes had glomeruli.

We also examined the antennal lobes of 4 animals that were allowed to progress to stage $15 / 16$ (Fig. 11) after receiving 400 Gy $\times 2$. The continued absence of glomeruli suggests that our results cannot be explained solely as a radiation-induced delay in development.

Finally, as another kind of control for possible nonspecific effects of radiation, we have begun preliminary experiments in which we have reduced the number of glial cells using a chemical antimitotic agent. In these experiments, hydroxyurea (Truman and Booker, 1986), which prevents conversion of ribonucleotides to deoxyribonucleotides, was injected into animals at stage $4 / 5$ and the antennal lobes examined at stage 12 . The neuropil of an antennal lobe in which the number of glial cells was decreased to roughly $45 \%$ of normal is only partially glomerular. Interestingly, the hydroxyurea-injected animals displayed many of the cuticular abnormalities seen in irradiated animals, indicating that the abnormalities result from interference with mitosis rather than direct cellular damage due to radiation.

\section{Discussion}

While interactions between neurons have been shown to be critical for normal development in numerous systems (Daphnia: Macagno, 1979; Flaster et al., 1982; Schistocerca: Anderson, 1978; cercal system in cricket: Murphey et al., 1975; Shankland et al., 1982; antennal system in Manduca: Hildebrand et al., 1979; Schneiderman et al., 1982; auditory system in cricket and chick: Levi-Montalcini, 1949; Hoy et al., 1978; somatosensory cortex and cerebellum in mouse: Rakic and Sidman, 1973; Van der Loos and Woolsey, 1973), in many cases it is not known whether the inductive interaction is a direct one or whether the interaction requires the mediation of another type of cell. We are testing the hypothesis, raised by our previous work (Oland and Tolbert, 1987), that glial cells play an intermediary role in the construction of the neuropil of the antennal lobe in Man$d u c a$. We ask, is any of the influence of the primary afferent axons on the glomerulization of antennal-lobe neurons effected via the glial cells?

Figure 12 summarizes our findings. The camera lucida drawings show the disposition of glial-cell nuclei and fine-textured neuropil in sections through representative normal, unafferented, and gamma-irradiated antennal lobes. In the presence of primary afferent axons $(A)$, the neuropil becomes glomerular. The glomeruli are the sites of synapses among the terminal arbors of afferent axons and the dense, spheroidal neuritic arbors of antennal-lobe neurons (Tolbert and Hildebrand, 1981). In the absence of afferent axons $(B)$, glomeruli do not develop. Nor do glomeruli develop in irradiated lobes $(C)$, despite the presence of afferent axons. The neuropil of the irradiated lobe strongly resembles that of the unafferented lobe in the lack of defined glomeruli, the disposition of fine- and coarse-textured regions of neuropil, and the loss of obvious boundaries between the 2 regions that is so characteristic of the normal lobe. On the other hand, the pattern of the diminished number of glial cells remaining in the irradiated lobe is typical of that seen in the normal lobe, where glial cells respond to the arrival of afferent axons by invading the neuropil. 

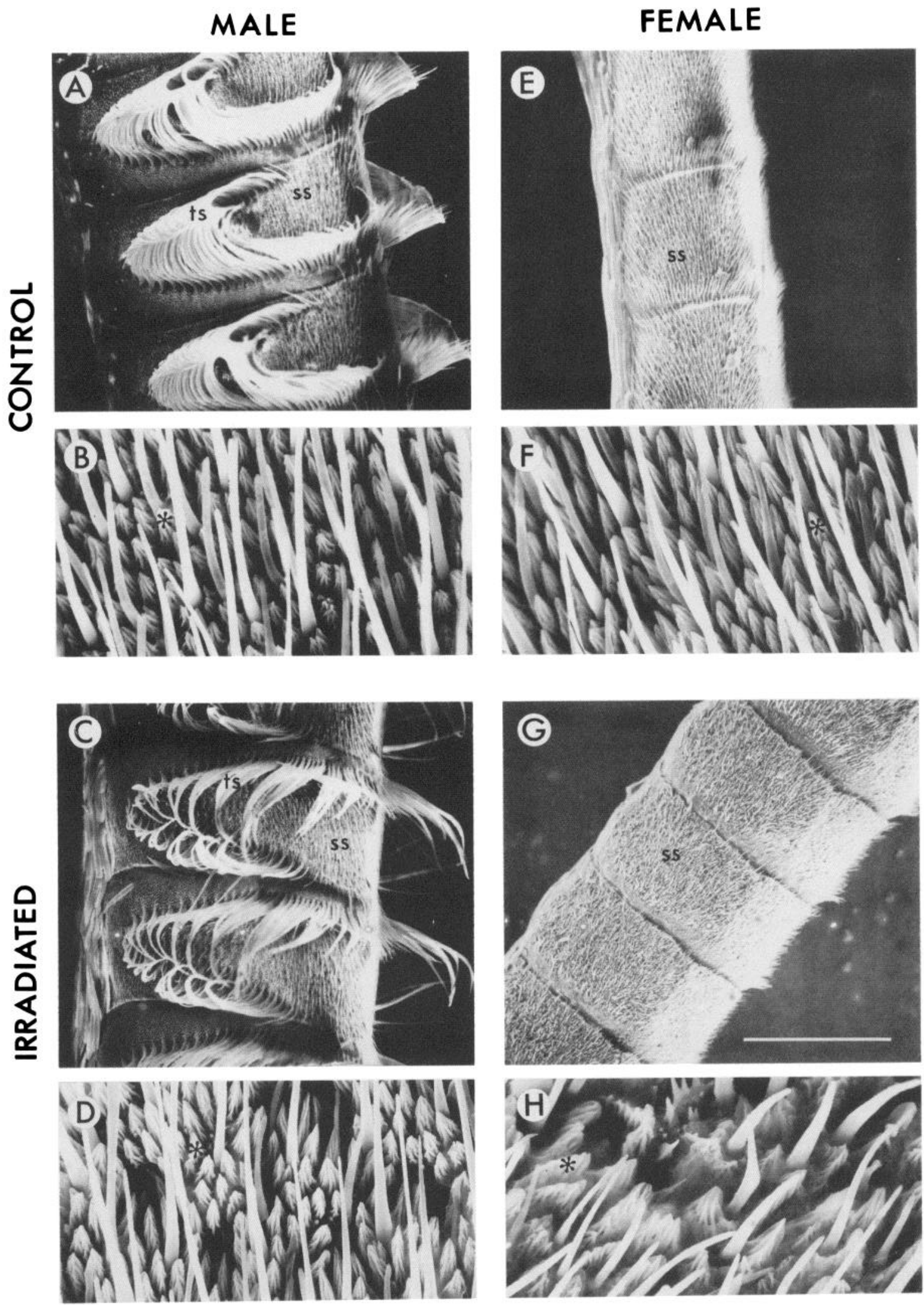

Figure 9. Scanning electron micrographs of segments of the antennal flagellum in normal animals and animals that had been exposed to 400 $\mathrm{Gy} \times 2$. Each pair shows a low-magnification view of several segments and a higher-magnification view of one segment. Scale bar, $310 \mu \mathrm{m}$ for $A$, $C, E, G ; 20 \mu \mathrm{m}$ for $B, D, F, H . A$ and $B$, Normal male, showing pattern of trichoid sensilla $(t s)$ and shorter sensilla (ss). ${ }^{*}$, microtrichium. $C$ and $D$, Irradiated male. $E$ and $F$, Normal female, showing shorter sensilla (ss). $G$ and $H$, Irradiated female. 

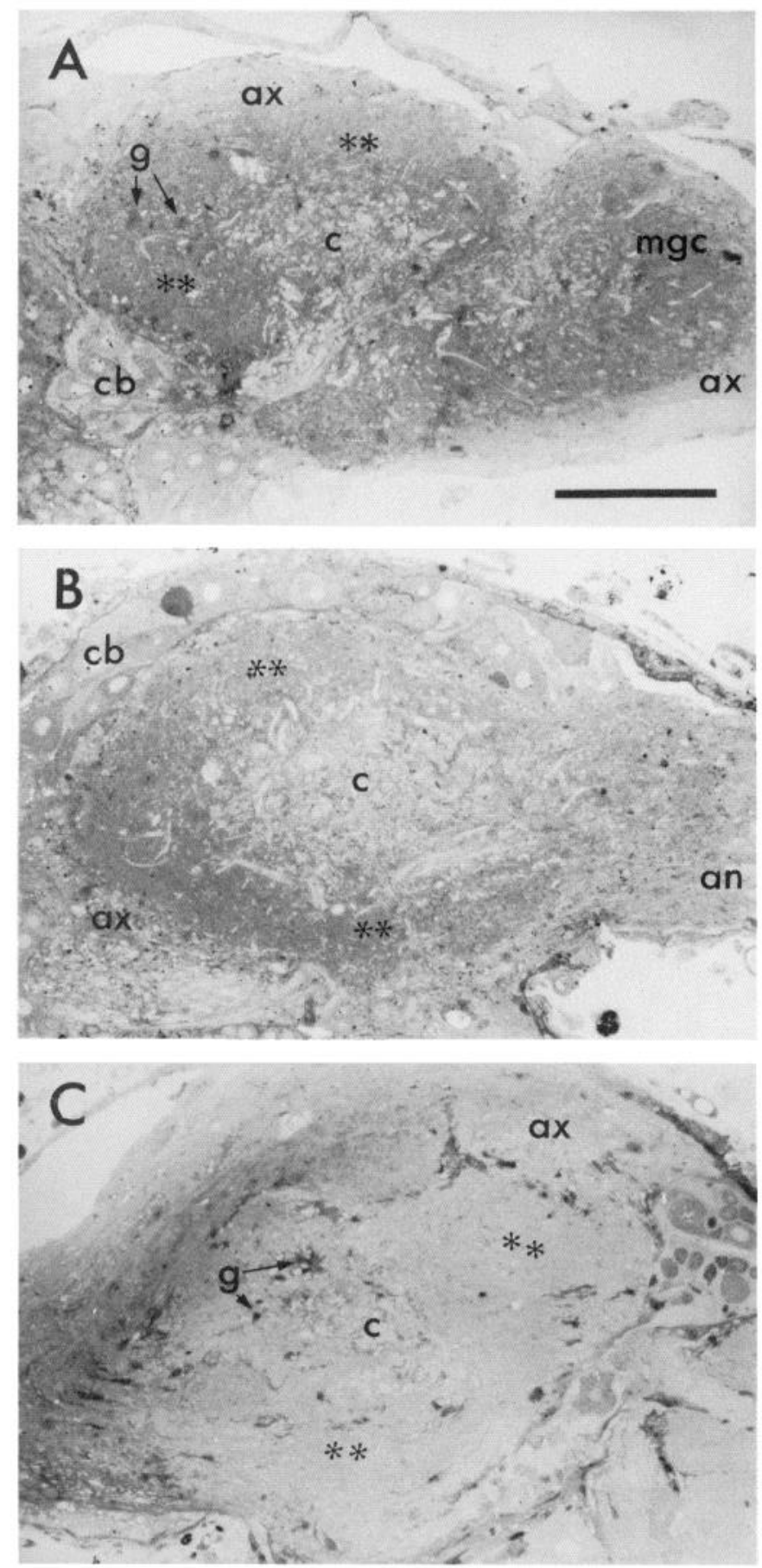

Figure 10. Histological sections from antennal lobes of animals that had been exposed to $400 \mathrm{~Gy} \times 2$ and for which the number of glial cells per cross section of the lobe and the number of nonmechanosensory afferent axons in the antennal nerve were counted. Scale bar, $100 \mu \mathrm{m}$ for all panels. $A$, Male, 63 glial cells per cross section; 76,000 afferent axons. $m g c$, macroglomerular complex. $B$, Male, 42 glial cells per cross section; 138,000 afferent axons. Macroglomerular complex is not in plane of section. $C$, Female, 53 glial cells per cross section; 148,000 afferent axons. $a x$, afferent axons; $c$, coarse neuropil; $c b$, cell bodies of antennal-lobe neurons; $g$, glia; ${ }^{* *}$, fine-textured neuropil; an, antennal nerve.

These results argue that glial cells do have a necessary role in the development of glomeruli. The strength of the argument depends upon the degree to which the effect of radiation is specific and limited to inhibition of glial mitosis.

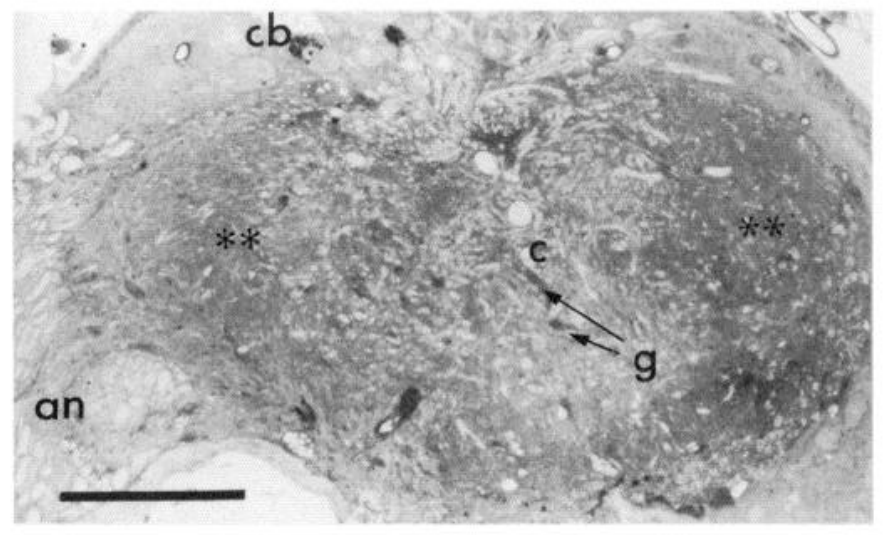

Figure 11. Histological section from antennal lobe of a stage $15 / 16$ animal that had been exposed to $400 \mathrm{~Gy} \times 2$. an, antennal nerve; $c$, coarse neuropil; $c b$, cell bodies of antennal-lobe neurons; $g$, glia; ${ }^{* *}$, fine-textured neuropil. Scale bar, $100 \mu \mathrm{m}$.

\section{General effects of radiation on the nervous system}

Studies of the effect of radiation on the nervous system have shown that it may be regarded as relatively radioresistant compared with other somatic tissues (Rubin and Casarett, 1968), except during the earliest stages of development, when neuroblasts, like other dividing cells, are exquisitely sensitive (Clemente and Richardson, 1962; Altman and Anderson, 1972). Effects on postmitotic neuronal elements include changes in excitability and decreases in conduction velocity and in regeneration capacity (Mastaglia et al., 1976; Edwards et al., 1984; Love and Gomez, 1984; Scaravilli et al., 1986). The neuroglia, on the other hand, are particularly susceptible, and a reduction in the number of glial cells consistently appears as a major effect of irradiation (Gilmore, 1963; Mastaglia et al., 1976; Gomez et al., 1982; Sims et al., 1985). The specific lesions underlying neuronal effects are not well understood, but it has been suggested that some might reflect indirect effects of damage to vascular tissue or of loss of glial cells rather than direct damage to the neurons (Masurovsky et al., 1967; Gomez et al., 1982; Scaravilli et al., 1986). Hypomyelination, for example, would be expected to reduce conduction velocity. Loss of glia also may be expected to disrupt the ionic microenvironment or interfere with some aspects of transmitter metabolism (Iverson and Kelly, 1975; Schousboe, 1981; Pentreath, 1982; Gray and Ritchie, 1985; Reynolds and Herschkowitz, 1986). The occurrence of such secondary effects on neurons due to the loss of glial cells in irradiated Manduca would not diminish our argument.

The doses we are using are high compared with those used in studies of the effects of radiation on mammalian tissue. However, insects, in general, and lepidopterans, in particular, show a remarkable degree of radioresistivity. Doses of 200-500 Gy, for example, are used to produce sterile but behaviorally viable males for field studies of methods to control the populations of agriculturally important moths (LaChance et al., 1967). It has been suggested that the resistivity of the lepidopterans is a function of a high chromosome number and the presence of holokinetic chromosomes (with diffuse centromeres) (LaChance et al., 1967).

\section{Evidence that radiation did not produce deafferentiation}

Because these experiments were aimed at testing whether glial cells play a role in the glomerulizing effect of antennal afferent 


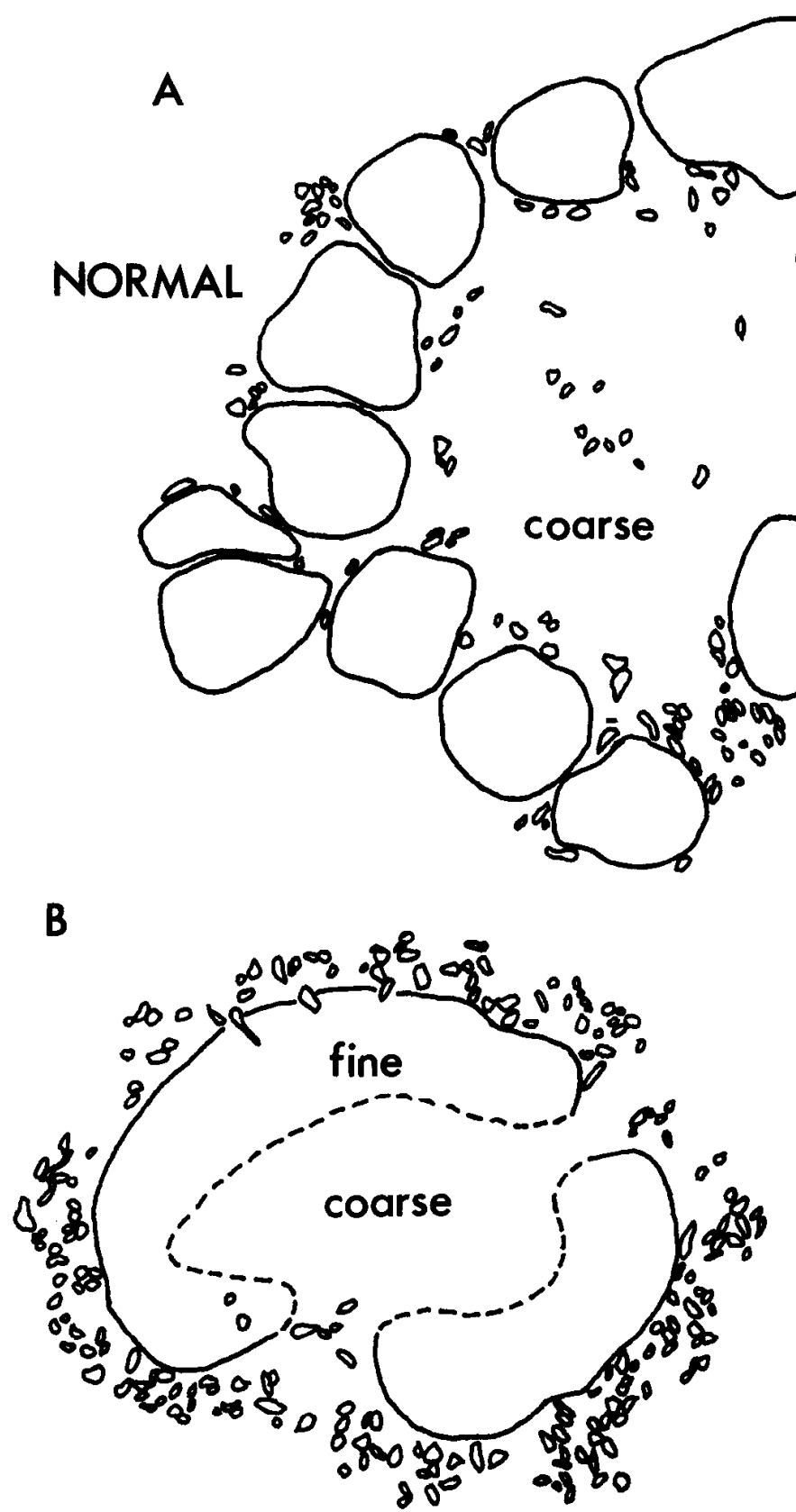

UNAFFERENTED

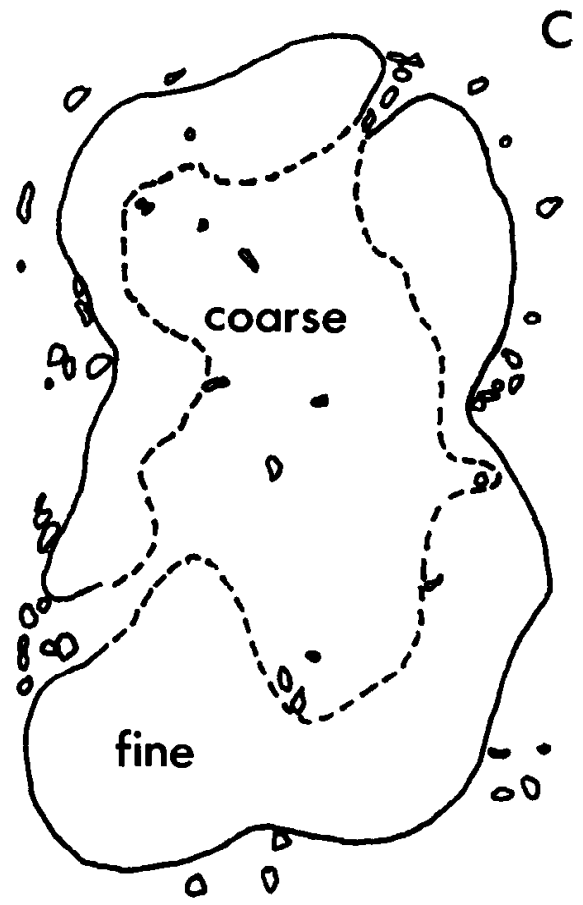

IRRADIATED

Figure 12. Camera lucida drawings of glial-cell nuclei in representative sections through normal $(A)$, unafferented $(B)$, and irradiated $(C)$ antennal lobes. Fine-textured synaptic neuropil is indicated by the enclosed regions; coarse neuropil occupies remaining central region. The nuclei of all neuropil-associated glial cells are drawn.

axons on the antennal lobe, and because we have found that glial-deficient lobes resemble unafferented lobes in many ways, it is important to know that the irradiated lobes received adequate afferent innervation.

The basic structure of the antenna, with its olfactory hairs innervated by sensory neurons, developed despite high doses of radiation. Only minor disruption of the cuticular elements of the antenna was found, this being not unexpected since at least some of the epidermal cells not associated with sensilla are dividing as late as $90 \mathrm{hr}$ after pupation (Sanes and Hildebrand, $1976 \mathrm{~b})$. The important finding is that we saw a complete absence of glomeruli in the antennal lobes from animals exposed to 400 Gy $\times 2$ in which gross anatomical and histological evidence of damage to the antennae was minimal. These lobes clearly provide the best test of our hypothesis.

The number of afferent axons present at stage $12 / 13$ in the antennal nerves of irradiated animals with complete antennae was never less than $30 \%$ of normal adult values. In another series of experiments, Tolbert (unpublished observations) found that typical glomeruli will develop in the presence of less than $10 \%$ of the normal number of afferent axons. Thus, the irradiated antennal lobes had a complement of axons more than 
sufficient to induce the development of glomeruli in unirradiated animals.

Were the afferent axons in irradiated antennae developmentally competent? Several of our findings suggest that it is likely that they were.

1. Afferent axons from the antenna continued to grow toward the antennal lobe, as shown by the increase in the number of axons in the antennal nerve between stage 4 , the time of irradiation (and the time when the first afferent axons reach the lobe), and stage 12, the age at which axons were counted in irradiated nerves. In addition, the majority of afferent axons were ultrastructurally indistinguishable from normal.

2. The consistent presence of the macroglomerular complex (MGC) in the antennal lobes of irradiated males (as in Fig. 11) strongly suggests that the ingrowing olfactory axons retain their ability to induce the differentiation of antennal-lobe neurons. As the MGC is not one of the ordinary glomeruli of the antennal lobe, differing from them in its histological appearance and in the absence of a clear glial envelope, the mechanisms by which it is constructed are unlikely to duplicate those involved in the formation of the ordinary glomeruli. Nevertheless, it is a region of antennal-lobe neuropil that comprises both antennal sensory axons and neurites of antennal-lobe neurons, and, most importantly, it does not develop except in the presence of sensory axons from the male-specific trichoid sensilla (Schneiderman et al., 1982).

3. The glial cells that remain in irradiated lobes do extend into the neuropil and many are found in the central region of the lobe. This behavior is characteristic of glial cells that have been exposed to afferent axons and is not seen in those that have not (Fig. 4, $A$ and $B$; Oland and Tolbert, 1987).

Taken together, these observations suggest that the failure of irradiated antennal lobes to develop glomeruli cannot be attributed to inadequate antennal input.

\section{Evidence that radiation did not compromise overall antennal-lobe development}

The failure of glomeruli to develop in irradiated animals is unlikely to reflect general developmental retardation, rather than the specific loss of glial cells. The antennal lobe that develops following irradiation has many mature features: The neuronal cell bodies are clustered normally, the neuropil has segregated into fine- and coarse-textured regions and in males contains an MGC, and the fine-textured neuropil contains multitudes of normal-appearing adult synapses. The cell bodies of neurons and, indeed, the cell bodies of the remaining glial cells display few, if any, signs of direct radiation damage. Major structures in the brain, including the mushroom bodies, the central body, and the optic lobes, also appear normal in gross structure.

Our preliminary experiments using hydroxyurea as an alternative method for reducing glial numbers circumvent possible complications of irradiation. The appearance of the neuropil in antennal lobes with about $45 \%$ of the normal number of glial cells was intermediate in appearance between that of lobes irradiated with 200 and with $400 \mathrm{~Gy}$, which would cause a comparable reduction in glial numbers. The apparent similarity of effect on the antennal-lobe architecture of both hydroxurea and radiation suggests that our results stem from a reduction in the mitotically vulnerable glial population rather than a nonspecific interference with development.

We see no evidence to suggest that our results are secondary to a disruption of the blood-brain barrier. Tritiated-thymidine experiments (L. A. Oland and L. P. Tolbert, unpublished observations) have shown that the perineurial cells that form the barrier (Lane and Swales, 1978) are mitotically active during stages 4 and 5 , when the animals in the present study were subjected to irradiation; the apparent health of the neuronal cell bodies in the antennal lobe and elsewhere in the brain, however, suggests that the integrity of the perineurium was not compromised.

The important role of hormones, in particular, ecdysone, in metamorphic development (Bollenbacher et al., 1981; Riddiford, 1983; Schwartz and Truman, 1983) has been well established. Although the responses to ecdysone of antennal-lobe neurons and antennal sensory axons in particular have not been characterized, the fact that the irradiated animals continue to follow their normal developmental program up through stage $15 / 16$ (through the pcriod of ecdysone-dependent development) lessens the likelihood that our results reflect a hormonally deficient environment.

\section{Conclusions}

The findings we have reported support our hypothesis that glial cells are necessary for the afferent-axon-induced formation of olfactory glomeruli in the antennal lobe. How might the glial cells be acting? We know that the ingrowth of afferent axons into the lobe causes glial cells to send out processes and migrate into the neuropil (Oland and Tolbert, 1987). The glomeruli might arise as neuronal processes are passively constrained to branch within the spheroidal barriers that these "activated" glial elements form. Another, more interesting, possibility is that the activated glial cells provide a signal, which is concentrated within the glial barriers, that induces branching of neurites, in a manner analogous to the induction of heavy neuronal branching by homotypic glial cells in vitro (Denis-Donini et al., 1984). In the absence of an adequate number of activated glial cells, the glia do not provide enough of the signal and/or are unable to form the barriers required for either of these mechanisms. Future studies involving examination of the branching patterns of afferent axons and of antennal-lobe neurons and in vitro manipulations of antennal-lobe neurons and glial cells will enable us to explore these possibilities.

\section{References}

Allen, M. M., and D. Higgins (1986) Ganglionic nonneuronal cells induce dendritic growth in cultured sympathetic neurons. Soc. Neurosci. Abstr. 12: 159.

Altman, J., and W. J. Anderson (1972) Experimental reorganization of the cerebellar cortex. I. Morphological effects of elimination of all microneurons with prolonged $\mathrm{x}$-irradiation started at birth. J. Comp. Neurol. 146: 355-406.

Anderson, H. (1978) Postembryonic development of the visual system of the locust, Schistocerca gregaria. II. An experimental investigation of the formation of the retina-lamina projection. J. Embryol. Exp. Morphol. 46: 147-170.

Bastiani, J., C. Coe, S. Helfand, and C. S. Goodman (1985) Neuronal specificity and growth cone guidance in grasshopper and Drosophila embryos. Trends Neurosci. 8: 257-266.

Berg, D. K. (1982) Cell death in neuronal development: Regulation by trophic factors. In Neuronal Development, N. C. Spitzer, ed., pp. 297-332, Plenum, New York

Bollenbacher, W. E., S. L. Smith, W. Goodman, and L. I. Gilbert (1981) Ecdysteroid titer during larval-pupal-adult development of the tobacco hornworm, Manduca sexta. Gen. Comp. Endocrinol. 44: 302306.

Boss, V. C., and J. T. Schmidt (1984) Activity and the formation of ocular dominance patches in dually innervated tectum of goldfish. $J$. Neurosci. 4: 2891-2905. 
Camazine, S. M., and J. G. Hildebrand (1979) Central projections of antennal sensory neurons in mature and developing Manduca sexta. Soc. Neurosci. Abstr. 5: 155.

Casarett, G. W. (1980) Radiation Histopathology, pp. 18-20, CRC Press, Boca Raton, FL.

Chambille, I., C. Masson, and J. P. Rospars (1980) The deutocerebrum of the cockroach Blaberus craniifer Brum. Spatial organization of the sensory glomeruli. J. Neurobiol. 11: 135-157.

Christensen, T. A., and J. G. Hildebrand (1984) Functional anatomy and physiology of male-specific pheromone-processing interneurons in the brain of Manduca sexta. Soc. Neurosci. Abstr. 10:862.

Clemente, C. D., and H. E. Richardson (1962) Response of the Nervous System to Ionizing Radiation, T. J. Haley and R. S. Snider, eds., pp. 411-428, Academic, New York.

Cowan, W. M., and E. Wenger (1967) Cell loss in trochlear nucleus of chick during normal development and after radical extirpation of the optic vesicle. J. Exp. Zool. 164: 267-280.

Denis-Donini, S., J. Glowinski, and A. Prochiantz (1984) Glial heterogeneity may define the three-dimensional shape of mouse mesencephalic dopaminergic neurones. Nature 307: 641-643.

Edwards, J. C., D. Chapman, W. A. Cramp, and M. B. Yatvin (1984) The effects of ionizing radiation on biomembrane structure and function. Prog. Biophys. Mol. Biol. 43: 71-93.

Edwards, J. S., and M. R. Meyer (1985) Developmental interactions between neurons in insects. In Molecular Bases of Neural Development, G. M. Edelman and W. E. Gall, eds., pp. 317-339, Plenum, New York.

Ernst, K.-D., J. Boeckh, and V. Boeckh (1977) A neuroanatomical study on the organization of the central antennal pathways in insects. II. Deutocerebral connection in Locusta migratoria and Periplaneta americana. Cell Tissue Res. 176: 285-308.

Fawcett, J. W., and D. D. M. O'Leary (1985) The role of electrical activity in the formation of topographic maps in the nervous system. Trends Neurosci. 8: 201-206.

Flaster, M. S., E. R. Macagno, and R. S. Schehr (1982) Mechanisms for the formation of synaptic connections in the isogenic nervous system of Daphnia magna. In Neuronal Development, N. C. Spitzer, ed., pp. 267-296, Plenum, New York.

Gilmore, S. A. (1963) The effects of $x$-irradiation on the spinal cords of neonatal rats. J. Neuropathol. Exp. Neurol. 22: 285-293.

Gomez, S., L. W. Duchen, and S. Hornsey (1982) Effects of x-irradiation on axonal sprouting induced by botulinum toxin. Neuroscience 7: 1023-1036.

Gray, P. T. A., and J. M. Ritchie (1985) Ion channels in Schwann and glial cells. Trends Neurosci. 8: 411-415.

Graziadei, P. P. C., and D. W. Samanen (1980) Ectopic glomerular structures in the olfactory bulb of neonatal and adult mice. Brain Res. 187: 467-472.

Hildebrand, J. G., and R. A. Montague (1986) Functional organization of olfactory pathways in the central nervous system of Manduca sexta. In Mechanisms in Insect Olfaction. T. Payne, M. Birch, and J. Kennedy, eds., pp. 279-285, Oxford U. P., New York.

Hildebrand, J. G., L. M. Hall, and B. C. Osmond. (1979) Distribution of bonding sites for ${ }^{125}$ I-labeled alpha-bungarotoxin in normal and deafferented antennal lobes of Manduca sexta. Proc. Natl. Acad. Sci. USA 76: 499-503.

Hoy, R., G. Cassaday, and S. Rollins (1978) Absence of auditory afferents alters the growth pattern of an identified auditory interneuron. Soc. Neurosci. Abstr. 4: 115.

Iverson, I. I., and J. S. Kelly (1975) Uptake and metabolism of GABA by neuron and glial cells. Biochem. Pharmacol. 24: 933-938.

Jacobson, M. (1978) Cellular interactions and interdependence during development of the nervous system. In Developmental Neurobiology, pp. 253-309, Plenum, New York.

Jefferies, D. J., and P. B. Cornwell (1958) Lethal and sterilizing effects of single and fractioned doses of gamma radiation in Caladra granaria L. Nature 182: 402-403.

Karnovsky, M. (1965) A formaldehyde-glutaraldehyde fixative of high osmolality for use in electron-microscopy. J. Cell. Biol. 27: 137A$138 \mathrm{~A}$.

Kent, K. S. (1985) Metamorphosis of the antennal center and the influence of sensory innervation on the formation of glomeruli in the hawk moth Manduca sexta. Ph.D. dissertation, Harvard University, Cambridge, MA

LaChance, L. E., C. H. Schmidt, and R. C. Bushland (1967) Radiation induced sterilization. In Pest Control: Biological, Physical and Selected Chemical Methods, W. W. Kilgore and R. L. Doutt, eds., pp. 181-190, Academic, New York.

Lancet, D., C. A. Greer, J. S. Kauer, and G. M. Shepherd (1982) Mapping of odor-related neuronal activity in the olfactory bulb by high resolution 2-deoxyglucose autoradiography. Proc. Natl. Acad. Sci. USA 79: 670-674

Lanc, N. J. (1981) Invertebrate ncuroglia-junctional structurc and development. J. Exp. Biol. 95: 7-33.

Lane, N. J., and L. S. Swales (1978) Changes in the blood-brain barrier of the central nervous system in the blowfly during development, with special reference to the formation and disaggregation of gap and tight junctions. II. Pupal development and adult flies. Dev. Biol. 62: 415431.

Levi-Montalcini, R. (1949) The development of the acoustico-vestibular centers in the chick embryo in the absence of the afferent root fibers and of descending fiber tracts. J. Comp. Neurol. 91: 209-242.

Lo Presti, V., E. R. Macagno, and C. Levinthal (1973) Structure and development of neuronal conncctions in isogenic organisms: Cellular interactions in the development of the optic lamina of Daphnia. Proc. Natl. Acad. Sci. USA 70:433-437.

Lo Presti, V., E. R. Macagno, and C. Levinthal (1974) Structure and development of neuronal connections in isogenic organisms: Transient gap junctions between growing optic axons and lamina neuroblasts. Proc. Natl. Acad. Sci. USA 71: 1098-1 102.

Love, S., and S. Gomez (1984) Effects of experimental radiationinduced hypomyelinating neuropathy on motor end-plates and neuromuscular transmission. J. Neurol. Sci. 65: 93-109.

Macagno, E. R. (1979) Cellular interactions and pattern formation in the development of the visual system of Daphnia magna (Crustacea Branchiopoda) I. Interactions between embryonic retinular fibers and laminar neurons. Dev. Biol. 73: 206-238.

Mastaglia, F. L., W. I. McDonald, J. V. Watson, and K. Yogendran (1976) Effects of $x$-radiation on the spinal cord: An experimental study of the morphological changes in the central nerve fibres. Brain 99: 101-122

Masurovsky, E. B., M. B. Bunge, and R. P. Bunge (1967) Cytological studies of organotypic cultures of rat dorsal root ganglia following $\mathrm{x}$-irradiation in vitro. I. Changes in neurons and satellite cells. J. Cell Biol. 32: 467-496.

Matsumoto, S. G., and J. G. Hildebrand (1981) Olfactory mechanisms in the moth Manduca sexta: Response characteristics and morphology of central neurons in the antennal lobes. Proc. R. Soc. Lond. [Biol.] 213: 249-277.

Mettler, F. A., and R. D. Moseley (1985) Medical Effects of Ionizing Radiation. p. 18, Grune \& Stratton, New York.

Mudge, A. (1984) Schwann cells induce morphological transformation of sensory neurones in vitro. Nature 309: 367-369.

Murphey, R. K., and C. A. Lemere (1984) Competition controls the growth of a identified axonal arborization. Science 224: 1352-1355.

Murphey, R. K., B. Mendenhall, J. Palka, and J. S. Edwards (1975) Deafferentation slows the growth of specific dendrites on identified giant interneurons. J. Comp. Neurol. 159: 407-418.

Nordlander, R. H., and M. Singer (1982) Morphology and position of growth cones in the developing Xenopus spinal cord. Dev. Brain Res. 4: 181-193.

Oland, L. A., and L. P. Tolbert (1986) Reduction of glial population by gamma-irradiation disrupts development of glomeruli in Manduca sexta antennal lobe. Soc. Neurosci. Abstr. 12: 929.

Oland, L. A., and L. P. Tolbert (1987) Glial patterns during early development of antennal lobes of Manduca sexta: A comparison between normal lobes and lobes derprived of antennal axons. J. Comp. Neurol. 255: 196-207.

Pentreath, V.W. (1982) Potassium signalling of metabolic interactions between neurons and glial cells. TINS 5: 339-345.

Purves, D., and J. W. Lichtman (1980) Elimination of synapses in the developing nervous system. Science 210: 153-157.

Purves, D., and J. W. Lichtman (1985) Principles of Neural Development, Sinauer, Sunderland, MA.

Quastel, M. R., and C. M. Pomerat (1963) Irradiation of cells in tissue culture. VIII. Morphological observations of neurons following cobalt-60 gamma irradiation of dorsal root ganglia from the newborn rat. Z. Zellforsch. 59: 214-223.

Rakic, $P$. (1971) Neuron-glia relationship during granule cell migration in developing cerebellar cortex: A Golgi and electromicroscopic study 
in Macacus rhesus. J. Comp. Neurol. 141: 283-312.

Rakic, P. (1981) Neuronal-glial interaction during brain development. Trends Neurosci. 4: 184-187.

Rakic, P., and R. L. Sidman (1973) Organization of cerebellar cortex secondary to deficit of granule cells in weaver mutant mice. J. Comp. Neurol. 152: 133-162.

Reh, T. A., and M. Constantine-Paton (1985) Eye-specific segregation requires neural activity in three-eyed Rana pipiens. J. Neurosci. 5: 1152-1166.

Reynolds, R., and N. Herschkowitz (1986) Selective uptake of neuroactive amino acids by both oligodendrocytes and astrocytes in primary dissociated culture: A possible role for oligodendrocytes in neurotransmitter metabolism. Brain Res. 371: 253-266.

Riddiford, L. M. (1983) Hormone action at the cellular level. In Comprehensive Insect Physiology, Biochemistry and Pharmacology, G. A. Kerkut and L. I. Gilbert, eds., Pergamon, New York.

Rubin, P., and A. Casarett (1968) Clinical Radiation Pathology, Saunders, Philadelphia.

Sanes, J. R., and J. G. Hildebrand (1976a) Structure and development of antennae in the moth, Manduca sexta. Dev. Biol. 51: 282-299.

Sanes, J. R., and J. G. Hildebrand (1976b) Origin and morphogenesis of sensory neurons in an insect antenna. Dev. Biol. 51: 300-319.

Scaravalli, F., S. Love, and R. Myers (1986) X-irradiation impairs regeneration of peripheral nerve across a gap. J. Neurocytol. 15: 439449.

Schneiderman, A. M., S. G. Matsumoto, and J. G. Hildebrand (1982) Trans-sexually grafted antennae influence the development of sexually dimorphic neuron in the brain of Manduca sexta. Nature 298: 844 846.

Schousboe, A. (1981) Transport and metabolism of glutamine and GABA in neurons and glial cells. Int. Rev. Neurobiol. 22: 1-45.

Schwartz, L. M., and J. W. Truman (1983) Hormonal control of rates of metamorphic development in the tobacco hornworn Manduca sexta. Dev. Biol. 99: 103-114.

Shankland, M., D. Bentley, and C. S. Goodman (1982) Afferent innervation shapes the dendritic branching pattern of the medial giant interneuron in grasshopper embryos raised in culture. Dev. Biol. 92: $507-520$

Silver, J., and R. L. Sidman (1980) A mechanism for the guidance and topographic patterning of retinal ganglionic cell axons. J. Comp. Neurol. 189: 101-112.

Sims, T., S. G. Waxman, J. A. Black, and S. A. Gilmore (1985) Perinodal astrocyte processes at nodes of Ranvier in developing normal and glial cell-deficient rat spinal cord. Brain Res. 337: 321-331.

Sretavan, D. W., and C. J. Shatz (1986) Prenatal development of retinal ganglion cell axons: Segregation into eye-specific layers within the cat's lateral geniculate nucleus. J. Neurosci. 6: 234-251.

Stewart, W. B., J. S. Kauer, and G. M. Shepherd (1979) Functional organization of the rat olfactory bulb analyzed by the 2-deoxyglucose method. J. Comp. Neurol. 185: 715-734.

Stocker, R. F., R. N. Singh, M. Schoderet, and O. Siddiqi (1983) Projection pattern of different types of antennal sensilla in the antennal glomeruli of Drosophila melanogaster. Cell Tissue Res. 232: 237248.

Strausfeld, N. (1976) Atlas of an Insect Brain, pp. 13-19, SpringerVerlag, Berlin.

Tolbert, L. P., and J. G. Hildebrand (1981) Organization and synaptic ultrastructure of glomeruli in the antennal lobes of the moth Manduca sexta: A study using thin sections and freeze-fracture. Proc. R. Soc. London [Biol.] 213: 279-301.

Tolbert, L. P., S. G. Matsumoto, and J. G. Hildebrand (1983) Development of synapses in the antennal lobes of the moth Manduca sexta during metamorphosis. J. Neurosci. 3: 1158-1175.

Truman, J. W., and R. Booker (1986) Adult-specific neurons in the nervous system of the moth, Manduca sexta: Selective chemical ablation using hydroxyurea. J. Neurobiol. 17: 613-625.

Van der Loos, H., and T. Woolsey (1973) Somatosensory cortex: Structural alterations following early injury to sense organs. Science 179: 395-398.

Wigglesworth, V. (1972) The Principles of Insect Physiology, pp. 181185, Chapman and Hall, London.

Woolsey, T. A., J. R. Anderson, J. R. Wann, and B. B. Stanfield (1979) The effects of early vibrissae damage on neurons in the ventrobasal (VB) thalamus of the mouse. J. Comp. Neurol. 184: 363-380.

Zacharuk, R. Y. (1985) Antennae and sensilla. In Comprehensive Insect Physiology, Biochemistry and Pharmacology, Vol. 6, G. A. Kerkut and L. I. Gilbert, eds., pp. 1-63, Pergamon, New York. 